\title{
Aerosol modeling with CHIMERE_-preliminary evaluation at the continental scale
}

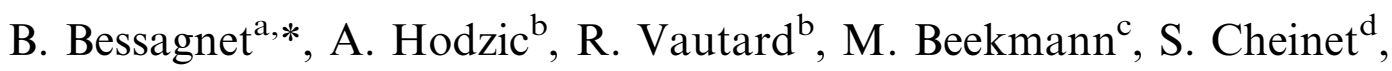 \\ C. Honoré ${ }^{\mathrm{a}}$, C. Liousse ${ }^{\mathrm{e}}$, L. Rouil ${ }^{\mathrm{a}}$

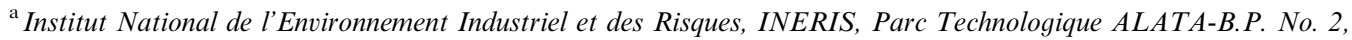 \\ 60550 Verneuil en Halatte, France \\ ${ }^{\mathrm{b}}$ Laboratoire de Météorologie Dynamique, Ecole Polytechnique, 91128 Palaiseau, France \\ ' Service d'Aéronomie, Université Pierre et Marie Curie, 4 place de Jussieu, 75252 Paris, France \\ ${ }^{\mathrm{d}}$ Laboratoire de Météorologie Dynamique, Université Pierre et Marie Curie, 4 place de Jussieu, 75252 Paris, France \\ ' Laboratoire d'Aérologie, Universite' Paul Sabatier, 14 avenue Edouard Belin, Toulouse 31400, France
}

\begin{abstract}
Aerosol modeling is a challenging scientific problem aimed at improving our knowledge in the many complex processes involved in multiphase chemistry and transport. Correct simulations of aerosols are also required in order to elaborate particle emission reduction strategies. The CHIMERE chemistry transport model (Atmos. Environ. 35 (2001) 6277) has been improved to account for particle transport, formation, deposition at the European scale. The aerosol model accounts both for inorganic $\left(\mathrm{NO}_{3}^{-}, \mathrm{SO}_{4}^{2}, \mathrm{NH}^{+}\right)$and rganic species of primary or secondary origin. Secondary organic aerosols from biogenic and anthropogenic gas precursors are partitioned into gas and particulate phases through a temperature dependent partition coefficient. The modeling approach is presented in this paper with preliminary simulation results over Europe. Comparisons with available data at background stations give acceptable results on $\mathrm{PM}_{10}$, with correlation coefficients usually exceeding 0.5 and normalized errors in the $30-80 \%$ range in many regions. However, results on sulfate, nitrate and ammonium species display less correct error statistics. Comparisons on sulfate concentrations give normalized errors in the range $30-80 \%$ in summer and less correct in winter. Temporal correlation coefficients usually range from 0.30 to 0.70 . Nitrate concentrations are better simulated during winter than during summer. Difficulties in simulating heterogeneous and aqueous phase processes could explain model deficiencies. Moreover, temperature dependence of gas/particle partitioning processes for nitrate, ammonium and secondary organic species could mainly explain the seasonal variability of biases. Model deficiencies are observed in Southern countries, certainly due to natural dust emissions and resuspended particles. Finally, sea salts seems to have a quite significant influence on error statistics in coastal areas.
\end{abstract}

Keywords: Aerosol model; Sectional approach; Heterogeneous and aqueous chemistry; Validation; Error statistics

\section{Introduction}

Suspended particles have recently received much interest because of increasing epidemiological and

\footnotetext{
*Corresponding author. Tel.: +33-344-55-65-33; fax: +33344-55-68-99.

E-mail address: bertrand.bessagnet@ineris.fr (B. Bessagnet).
}

experimental evidence of their health impact. According to recent health studies (Moshammer and Neuberger, 2003 and references therein), the $\mathrm{PM}_{10}$ standard concentration measurements (concentrations of particles below $10 \mu \mathrm{m}$ ) seems to be an inadequate indicator. Indeed, characteristics on masses, numbers, and even surfaces of fine particles have been shown to correlate with acute health effects and measurable functional 
changes in the cardiovascular and respiratory systems. Moreover, particles act on climate change by affecting the Earth's radiative balance, directly by altering the scattering properties of the atmosphere, and indirectly by changing cloud properties (Krüger and Graß1, 2002). Atmospheric particles recently introduced in air quality indicators through the $\mathrm{PM}_{10}$ norm could incorporate smaller particles in the future through the $\mathrm{PM}_{2.5}$ norm.

Scientists have developed modeling tools to better understand physical-chemical processes involving gaseous and particulate species and improve the prediction of pollution episodes. Seigneur (2001) reviews the current status of the mathematical modeling of atmospheric particulate matter and their ability to simulate pollution episodes. This review suggests that several models (Jacobson, 1997; Pai et al., 2000; Ackermann et al., 1998; Meng et al., 1998) provide a fairly comprehensive treatment of the major processes. For a reference smog episode, Seigneur (2001) has compared five models: these modeling results give normalized errors in the range $15-70 \%$, and normalized biases in the range $-50-+50 \%$ for nitrate, sulfate and $\mathrm{PM}_{2.5}$. Uncertainties remain, particularly for secondary organic aerosol (SOA) formation. About validation of modeling results for long-term simulations, Seigneur (2001) relates less correct statistical errors with fractional errors exceeding $100 \%$ in particular for nitrate. Up to now, correlation coefficients are rarely reported in the literature. However, a recent contribution to EUROTRAC 2 (Hass et al., 2003) provides correlation coefficient for various European models at EMEP sites for sulfate, nitrate, ammonium, $\mathrm{NO}_{2}$ and $\mathrm{SO}_{2}$, for summer 1995.

In this paper, a large-scale modeling system is developed to be used in the future to define particle emissions reduction strategies over Europe. The model is run at the scale of the European continent over a large time period in order to quantitatively assess its systematical strengths and weaknesses. This constraint puts requirements of low computational cost on the model, which implies simplifications in its formulation. The CHIMERE model approach (Schmidt et al., 2001) meets these requirements for ozone simulation and forecasting. However, in Schmidt et al. (2001) only the gas-phase chemistry is considered. We describe here the extension of the model to aerosols.

In Section 2, the aerosol module implemented in CHIMERE is described. This model is an improved version of the module described for zero-dimensional (0-D) applications in Bessagnet and Rosset (2001). A preliminary evaluation at the continental scale over Europe for 1999 is proposed in Section 3. Comparisons on sulfate, nitrate and ammonium species at several EMEP stations have been carried out (EMEP is the Cooperative Programme for Monitoring and Evaluation of the Long-range Transmission of Air Pollutants in
Europe). Modeling results on $\mathrm{PM}_{10}$ are also compared to available data at EMEP stations. This study gives an order of magnitude of statistical errors expected with CHIMERE-aerosol at the continental scale and tries to explain the main error sources.

\section{CHIMERE model and its aerosol module}

\subsection{Gas-phase chemistry transport model}

Most of the physics and chemistry of the CHIMERE gas-phase model is described in Schmidt et al. (2001) and Vautard et al. (2001). However, several updates have been achieved since these papers have been written. Some are described in Vautard et al. (2003). We briefly describe here the gas-phase model and the modifications relative to these two articles. The source code is available for download on the web site: http://euler. lmd.polytechnique.fr/chimere, where a more complete documentation for the model version used here is available (version named "V200310F").

CHIMERE is a 3-D Chemistry Transport Model computing, given a set of $\mathrm{NO}_{x}, \mathrm{VOCs}$ and $\mathrm{CO}$ emissions, the concentrations of 44 gas-phase species, on a regular grid $\left(0.5^{\circ} \times 0.5^{\circ}\right.$ here $)$. It uses eight hybrid sigma-pressure levels up to $700 \mathrm{hPa}$, thus encompassing the boundary layer. In this study, the horizontal extent covers, most of Western Europe from $10^{\circ} \mathrm{E} 30^{\prime}$ to $24^{\circ} \mathrm{W}$ and $36^{\circ} \mathrm{N}$ to $57^{\circ} 30^{\prime}$.

The set of chemical reactions follows the work of Lattuati (1997) (a modified version of the mechanism proposed by Hov et al., 1985) with updated reaction rates. Clear-sky photolysis rates are now tabulated from the Tropospheric Ultraviolet and Visible model (TUV, Madronich and Flocke, 1998) and depend on altitude. As described by Schmidt et al. (2001), the model columns are assumed to lie "below the clouds" since cloud effects on photolysis rates are taken into account using a single attenuation coefficient throughout a model column. All photolysis rates are modulated as

$J=J_{\mathrm{c}}(\zeta, z) \exp \left(-a D^{2 / 3}\right)$,

where $J_{\mathrm{c}}(\zeta, z)$ is the clear-sky photolysis rate, depending on zenith angle $\zeta$ and altitude $z, D$ is the cloud optical depth and $a=0.11$ is an adjusted coefficient obtained by regression from several TUV calculations with various cloud hypotheses.

Physical processes include transport, turbulent diffusion and dry deposition. Transport is solved using the Parabolic Piecewise Method for slow species. Vertical diffusion is now parameterized using a diffusivity profile (Troen and Mahrt, 1986), depending on boundary layer height, roughness velocity and convective velocity scale. The boundary layer height is calculated, in stable boundary layers, as in Troen and Mahrt (1986), and 
from a simplified version of the thermal formulation of Cheinet (2002) for convective boundary layers. Wesely's (1989) formulation for dry deposition is used. Lateral boundary conditions are monthly average values of the climatological simulations by the second-generation MOZART model (Horowitz et al., 2003).

Finally, all terrain-based processes (deposition, biogenic emissions, roughness) now use the $1 \mathrm{~km}$ GLCF data set (Global Land Cover Facility, Hansen et al., 2000; accessible data via internet at http://glcf.umiacs. umd.edu) aggregated to the model grid.

\subsection{Emissions}

The 1999 anthropogenic emission data from the EMEP database have been used. They consist of annual emitted quantities, given for the 11 SNAP activity sectors and $\mathrm{NO}_{x}, \mathrm{CO}, \mathrm{SO}_{x}, \mathrm{NMVOC}$ and $\mathrm{NH}_{3}$ families and species. Calculation of model species emissions is made in several steps. First, the spatial emission distribution from the EMEP grid to the CHIMERE grid is performed using an intermediate fine grid at $1 \mathrm{~km}$ resolution. Soil type being known on the fine grid allows for a better apportionment of the emissions according to urban, rural, maritime and continental areas. This highresolution land use inventory again comes from the GLCF data set. Time profiles of $\mathrm{NO}_{x}, \mathrm{CO}, \mathrm{SO}_{x}$ and NMVOC are considered depending on SNAP activity sectors and are provided by the IER (University of Stuttgart). For $\mathrm{NH}_{3}$, no time variability is considered. According to Aumont et al. (2003) HONO emission is set to $0.8 \%$ of $\mathrm{NO}_{x}$ while $\mathrm{NO}_{2}$ emission is set to $9.2 \%$ of $\mathrm{NO}_{x}$ emissions, the remaining $\mathrm{NO}_{x}$ emissions being $\mathrm{NO}$. Afterwards, for each SNAP activity sector, the total NMVOC emission is splitted into emissions of 227 real individual NMVOC according to the AEAT speciation (AEAT, 2002). Finally, real species emissions are aggregated into model species emissions. For example, the MELCHIOR chemical mechanism takes into account 10 NMVOC. Mass-reactivity weighting of real emission data is done following the methodology of Middleton et al. (1990), so that the overall ozone production capability of the emission mixes is kept constant through the emission processing procedure.

Biogenic emissions are computed according to the methodology described in Simpson et al. (1995), for $\alpha$-pinene, NO and isoprene. First, they are computed for standard meteorological conditions, using vegetation and soil inventories (Simpson et al., 1999) of the model domain; then, these emissions are tuned according to the meteorological conditions prevailing during the simulation period.

Finally, the primary particle inventory is provided by TNO (Netherlands Organisation for Applied Scientific Research). Three emission classes are provided: $\mathrm{PM}_{2.5}$, $\mathrm{PM}_{10}$ and total suspended particles (TSP). Primary particle material (PPM) is composed of anthropogenic primary species including not only black carbon and organic carbon but also industrial mineral dusts.

\subsection{Meteorological inputs}

Our simulations are forced by European Center for Medium Range Weather Forecast (ECMWF) shortterm forecasts ( 3 and $6 \mathrm{~h}$ forecasts). Three-dimensional winds, temperature, humidity and cloud liquid water content are used throughout the model domain volume. These short-term forecasts, given with a 3-h time step, are linearly interpolated in time and space to the model grid. Some ECMWF 2-D fields are also used: high and medium cloud cover are used for the calculation of cloud optical depth, surface sensible and latent heat fluxes are used for the calculation of surface similarity parameters and the boundary layer height $(2 \mathrm{~m})$ temperature is used for deposition and for biogenic emissions, and total precipitation is used for gas and aerosol scavenging. Meteorological data are initially taken from the "model level" ECMWF database, and then averaged into the eight CHIMERE model layers.

\subsection{Composition and mathematical representation of aerosols}

Atmospheric aerosols are represented by their size distributions and compositions. The sectional representation described by Gelbard and Seinfeld (1980) has been used for the density distribution function. The sectional approach is quite useful to solve the governing equation for multicomponent aerosols. It discretizes the density distribution in a finite number of bins (Warren, 1986). Thus, all particles in section $l$ have the same composition and are characterized by their mean diameter $d_{l}$. The aerosol module actually uses six bins from $10 \mathrm{~nm}$ to $40 \mu \mathrm{m}$, following a geometrical progression. For a given $x$ as $x=\ln (m)$, with $m$ the particle mass, $q(x)$ is the density distribution as defined in Eq. (2), $Q$ being the mass concentration function. In the paper, $Q_{l}^{k}\left(\mu \mathrm{g} \mathrm{m}^{-3}\right)$ is the mass concentration of component $k$ in section $l$ and $Q_{1}\left(\mu \mathrm{g} \mathrm{m}^{-3}\right)$ is the total mass concentration in section $l$ (Eq. (3)).

$q(x)=\frac{\mathrm{d} Q}{\mathrm{~d} x}$,
$Q_{l}=\int_{x_{l-1}}^{x_{l}} q(x) \mathrm{d} x=\sum_{k} Q_{l}^{k}$.

In the model, particles are composed of species listed in Table 1. Sulfate is formed through gaseous and aqueous oxidation of $\mathrm{SO}_{2}$ (cf. Section 2.8.1). Nitric acid is produced in the gas phase by $\mathrm{NO}_{x}$ oxidation. $\mathrm{N}_{2} \mathrm{O}_{5}$ is converted into nitric acid via heterogeneous pathways by oxidation on aqueous aerosols (described 
Table 1

List of aerosol species

\begin{tabular}{|c|c|c|}
\hline Model species & Species & Type \\
\hline pPPM & $\begin{array}{l}\text { Anthropogenic primary } \\
\text { species } \\
\text { EC, OCp, and other } \\
\text { industrial dusts }\end{array}$ & Primary \\
\hline pSOA & $\begin{array}{l}\text { Anthropogenic and } \\
\text { biogenic secondary } \\
\text { organic aerosol } \\
\text { (ASOA + BSOA) }\end{array}$ & Secondary \\
\hline $\mathrm{pH}_{2} \mathrm{SO}_{4}$ & Equivalent sulfate $^{\mathrm{a}}$ & Secondary \\
\hline $\mathrm{pHNO}_{3}$ & Equivalent nitrate $^{\mathrm{a}}$ & Secondary \\
\hline $\mathrm{pNH}_{3}$ & Equivalent ammonium $^{\mathrm{a}}$ & $\begin{array}{l}\text { Primary emitted, } \\
\text { secondary } \\
\text { transferred }\end{array}$ \\
\hline pWATER & Water & - \\
\hline
\end{tabular}

${ }^{\mathrm{a}}$ Ions, molecules, crystals.

in Section 2.8.2). Ammonia is a primary emitted base converted in the aerosol phase by neutralization with nitric and sulfuric acids. Ammonia, nitrate and sulfate exist in aqueous, gaseous and particulate phases in the model. As an example, in the particulate phase the model species $\mathrm{pNH}_{3}$ represents an equivalent ammonium as the sum of $\mathrm{NH}_{4}^{+}$ion, $\mathrm{NH}_{3}$ liquid, $\mathrm{NH}_{4} \mathrm{NO}_{3}$ solid, etc.

\subsection{Coagulation}

Since $Q_{l}^{k}$ is the mass concentration of component $k$ in section $l$, the mass balance equation for coagulation (Gelbard and Seinfeld, 1980) follows Eq. (4):

$$
\begin{aligned}
{\left[\frac{\mathrm{d} Q_{l}^{k}}{\mathrm{~d} t}\right]_{\mathrm{coag}}=} & \frac{1}{2} \sum_{i=1}^{l-1} \sum_{j=1}^{l-1}\left[{ }^{1 a} \beta_{i, j, l} Q_{j}^{k} Q_{i}+{ }^{1 b} \beta_{i, j, l} Q_{i}^{k} Q_{j}\right] \\
& -\sum_{i=1}^{l-1}\left[{ }^{2 a} \beta_{i, l} Q_{i} Q_{l}^{k}-{ }^{2 b} \beta_{i, l} Q_{l} Q_{i}^{k}\right] \\
& -\frac{1}{2}{ }^{3} \beta_{l, l} Q_{l} Q_{l}^{k}-Q_{l}^{k} \sum_{i=l+1}^{m}{ }^{4} \beta_{i, l} Q_{i} .
\end{aligned}
$$

The sectional coagulation coefficients ${ }^{1 a} \beta,{ }^{1 b} \beta,{ }^{2 a} \beta,{ }^{2 b} \beta$, ${ }^{3} \beta$ and ${ }^{4} \beta$ (Fuch, 1964) depend on particle characteristics and meteorological data such as temperature, pressure and turbulence parameters. For submicronic particles, coagulation is essentially driven by Brownian motions. For coarse particles sedimentation is an efficient process.

\subsection{Absorption process}

The absorption flux $J\left(\mu \mathrm{g} \mathrm{m}^{-3} \mathrm{~s}^{-1}\right)$ of a semi-volatile inorganic or organic species onto a monodisperse aerosol is

$J=\frac{1}{\tau}\left(G-G_{\text {eq }}\right)$

with $G$ and $G_{\text {eq }}\left(\mu \mathrm{g} \mathrm{m}^{-3}\right)$, respectively, are the gas phase and equilibrium concentrations. The characteristic time $\tau$ is

$\tau=\frac{(1+(8 \lambda / \alpha d))}{2 \pi \lambda c d N}$

with $\lambda(\mathrm{m})$ is the mean free path of air molecules, $d(\mathrm{~m})$ the particle diameter, $N$ (particle $\mathrm{m}^{-3}$ ) the particle number concentration, $\alpha$ the accommodation coefficient of the transferred species and $c\left(\mathrm{~m} \mathrm{~s}^{-1}\right)$, its mean molecular velocity. For a semi-volatile species $k$, a mean absorption coefficient $H_{l}^{k}\left(\mathrm{~s}^{-1}\right)$ is defined at section $l$ as

$\left[\frac{\mathrm{d} Q_{l}^{k}}{\mathrm{~d} t}\right]_{\text {abso }}=H_{l}^{k} Q_{l}$,

$H_{l}^{k}=\frac{12 \lambda c_{k}}{\rho_{\mathrm{p}} d_{l}^{2}\left(1+\left(8 \lambda / \alpha_{k} d_{l}\right)\right)}\left(G^{k}-G_{l, \mathrm{eq}}^{k}\right)$,

where $\rho_{\mathrm{p}}$ is the particle density (fixed at $1500 \mathrm{~kg} \mathrm{~m}^{-3}$ here).

For semi-volatile inorganic species (sulfate, nitrate, ammonium), the equilibrium concentration $G_{\mathrm{eq}}$ is calculated using the thermodynamic module ISORROPIA (Nenes et al., 1998). This model also determines the water content of particles. Interactions between inorganic and organic species are not taken into account, the thermodynamic of such mixtures still being poorly understood. Equilibrium concentrations for the semivolatile organic species $k$ are related to particle concentrations through a temperature dependent partition coefficient $K^{\mathrm{p}}$ (in $\mathrm{m}^{3} \mu \mathrm{g}^{-1}$ ) (Pankow, 1994):

$G_{l, \mathrm{eq}}^{k}=\frac{Q_{l}^{k}}{\mathrm{OM}_{l} K_{k}^{\mathrm{p}}}$

with $\mathrm{OM}\left(\mu \mathrm{g} \mathrm{m}^{-3}\right)$ is the absorbent organic material concentration. Considering the thermodynamic equilibrium between the gas and particulate phases, this coefficient is given by

$K_{k}^{\mathrm{p}}=\frac{10^{-6} R T}{\mathrm{MW}_{\mathrm{om}} \zeta_{k} p_{k}^{0}}$

with $R$ is the ideal gas constant $(8.206 \times$ $10^{-5} \mathrm{~m}^{3}$ atm $\left.\mathrm{mol}^{-1} \mathrm{~K}^{-1}\right), T$ the temperature (K), $\mathrm{MW}_{\text {om }}$ the mean molecular weight $\left(\mathrm{g} \mathrm{mol}^{-1}\right), p_{i}^{0}$ the vapor pressure of product $i$ as a pure liquid (atm) and $\zeta$ the activity coefficient of species in the bulk aerosol phase. The coefficient $\zeta$, difficult to calculate, is assumed constant and equal to unity. Moreover, an empirical formulae can be used to estimate $K^{\mathrm{p}}$ :

$\log \left(K^{\mathrm{p}}\right)=-0.61 \log \left(p^{0}\right)-4.74$

according to Kaupp and Umlauf (1992) for organic species. 


\subsection{Nucleation}

The parameterization of Kulmala et al. (1998) for sulfuric acid nucleation is used. This process, favored by cold humid atmospheric conditions, affects the number of ultrafine particles. The nucleated flux is added to the smallest bin in the sectional distribution. Nucleation of condensable organic species has been clearly identified in many experimental studies (Kavouras et al., 1998), there is no available parameterization. Since, the sulfuric acid nucleation process competes with absorption processes, it is expected to occur in weakly particle polluted conditions.

\subsection{Multiphase chemistry}

\subsubsection{Sulfur aqueous chemistry}

Sulfate is produced in the gas phase by reactions

$\mathrm{SO}_{2}+\mathrm{OH} \rightarrow \mathrm{H}_{2} \mathrm{SO}_{4}$,

$\mathrm{SO}_{2}+\mathrm{CH}_{3} \mathrm{O}_{2} \rightarrow \mathrm{H}_{2} \mathrm{SO}_{4}+\mathrm{HCHO}$

and also in aqueous reactions (Berge, 1993; Hoffman and Calvert, 1985; Lee and Schwartz, 1983)

$\mathrm{SO}_{2}^{\mathrm{aq}}+\mathrm{O}_{3}^{\mathrm{aq}} \rightarrow \mathrm{SO}_{4}^{2-}$,

$\mathrm{HSO}_{3}^{-}+\mathrm{O}_{3}^{\mathrm{aq}} \rightarrow \mathrm{SO}_{4}^{2-}$,

$\mathrm{SO}_{3}^{2-}+\mathrm{O}_{3}^{\mathrm{aq}} \rightarrow \mathrm{SO}_{4}^{2-}$,

$\mathrm{SO}_{2}^{\mathrm{aq}}+\mathrm{H}_{2} \mathrm{O}_{2}^{\mathrm{aq}} \rightarrow \mathrm{SO}_{4}^{2-}$,

$\mathrm{SO}_{2}^{\mathrm{aq}}+\mathrm{NO}_{2}^{\mathrm{aq}} \rightarrow \mathrm{SO}_{4}^{2-}$,

$\mathrm{SO}_{2}, \mathrm{H}_{2} \mathrm{O}_{2}$ and $\mathrm{O}_{3}$ in the gas phase are in equilibrium with the aqueous phase. Moreover, aqueous $\mathrm{SO}_{2}$ is dissociated into $\mathrm{HSO}_{3}^{-}$and $\mathrm{SO}_{3}^{2-}$. Henry's law coefficient and other aqueous equilibrium constants are listed in Table 2 (Seinfeld and Pandis, 1998). Sulfur chemistry is very $\mathrm{pH}$ sensitive: in our model, the $\mathrm{pH}$ is estimated by solving the charge balance equation in the aqueous phase. Catalyzed oxidation reactions of sulfur dioxide in aqueous droplets with iron $\left(\mathrm{Fe}^{2+}\right)$ and manganese $\left(\mathrm{Mn}^{2+}\right)$ have been implemented according to Martin et al. (1991), Martin and Hill (1987) and Hoffman and Calvert (1985):

$\mathrm{SO}_{3}^{2-} \stackrel{\mathrm{Fe}^{3+}}{\rightarrow} \mathrm{SO}_{4}^{2-}$,

$\mathrm{HSO}_{3}^{-} \stackrel{\mathrm{Mn}^{2+}}{\longrightarrow} \mathrm{SO}_{4}^{2-}$

\subsubsection{Heterogeneous chemistry}

Although aerosol particles and cloud droplets occupy a very small fraction of the atmosphere, it is now well established that reactions involving gas species onto their surfaces may significantly contribute to atmospheric chemistry cycles. Jacob (2000) recommends for ozone model to include a minimal set of reactions with associated uptake coefficients given by Harrison and Collins (1998), and other references in Jacob (2000):

$$
\begin{aligned}
& \mathrm{HO}_{2} \rightarrow 0.5 \mathrm{H}_{2} \mathrm{O}_{2}, \quad \gamma=0.2, \\
& \mathrm{NO}_{3} \rightarrow \mathrm{HNO}_{3}, \quad \gamma=10^{-3}, \\
& \mathrm{NO}_{2} \rightarrow 0.5 \mathrm{HNO}_{3}+0.5 \mathrm{HONO}, \quad \gamma=10^{-5}, \\
& \mathrm{~N}_{2} \mathrm{O}_{5} \rightarrow \text { cloud }
\end{aligned}
$$

The first-order rate constant $k$ for gas heterogeneous loss onto particles is given by

$k=\sum_{l}\left(\frac{d_{l}}{2 D_{\mathrm{g}}}+\frac{4}{v \gamma}\right)^{-1} A_{l}$

with $d_{l}$ is the particle diameter $(\mathrm{m}), D_{\mathrm{g}}$ the reacting gas molecular diffusivity $\left(\mathrm{m}^{2} \mathrm{~s}^{-1}\right), v$ the mean molecular velocity $\left(\mathrm{m} \mathrm{s}^{-1}\right), A_{l}$ the total surface area in the particle bin $l$ and $\gamma$, the uptake coefficient of reactive species. The uptake coefficient for Eq. (R13) is assumed to be temperature dependent in the range 0.01-1 (De More et al., 1997) with increasing values for decreasing temperatures. A recent study (Aumont et al., 2003) suggests that $\mathrm{NO}_{2}$ reactions onto ground surfaces could

Table 2

Thermodynamic data for aqueous equilibrium constant

\begin{tabular}{llc}
\hline Reactions & Equilibrium constants at $298 \mathrm{~K}$ & Heat of reactions $\Delta H_{298 \mathrm{~K}}$ in $\mathrm{kcal} \mathrm{mol}^{-1}$ \\
\hline $\mathrm{SO}_{2}^{\mathrm{g}} \rightleftharpoons \mathrm{SO}_{2}^{\mathrm{aq}}$ & $H=1.23 \mathrm{M} \mathrm{atm}^{-1}$ & -6.25 \\
$\mathrm{H}_{2} \mathrm{O}_{2}^{\mathrm{g}} \rightleftharpoons \mathrm{H}_{2} \mathrm{O}_{2}^{\mathrm{aq}}$ & $H=7.45 \times 10^{4} \mathrm{M} \mathrm{atm}^{-1}$ & -14.50 \\
$\mathrm{NH}_{3}^{\mathrm{g}} \rightleftharpoons \mathrm{NH}_{3}^{\mathrm{aq}}$ & $H=6.2 \times 10^{1} \mathrm{M} \mathrm{atm}^{-1}$ & -8.17 \\
$\mathrm{HNO}_{3}^{\mathrm{g}} \rightleftharpoons \mathrm{HNO}_{3}^{\mathrm{aq}}$ & $H=2.1 \times 10^{5} \mathrm{M} \mathrm{atm}^{-1}$ & -17.30 \\
$\mathrm{O}_{3}^{\mathrm{g}} \rightleftharpoons \mathrm{O}_{3}^{\mathrm{aq}}$ & $H=1.13 \times 10^{-2} \mathrm{M} \mathrm{atm}$ & -5.04 \\
$\mathrm{SO}_{2}^{\mathrm{aq}}+\mathrm{H}_{2} \mathrm{O} \rightleftharpoons \mathrm{H}^{+}+\mathrm{HSO}_{3}^{-}$ & $K_{\mathrm{A}}=1.3 \times 10^{-2} \mathrm{M}$ & -4.16 \\
$\mathrm{HSO}_{3}^{-}+\mathrm{H}_{2} \mathrm{O} \rightleftharpoons \mathrm{H}^{+}+\mathrm{SO}_{3}^{2-}$ & $K_{\mathrm{A}}=6.6 \times 10^{-8} \mathrm{M}$ & -2.23
\end{tabular}

$H$ : Henry's constant; $K_{\mathrm{A}}$ : dissociation constant. 
be an important source for HONO production during wintertime smog episodes, so, a new reaction is added:

$$
\mathrm{NO}_{2} \rightarrow \mathrm{HONO}
$$

with a reaction rate $k_{\mathrm{g}}\left(\mathrm{s}^{-1}\right)$ given by

$$
k_{\mathrm{g}}=0.5 \frac{v_{\mathrm{d}}}{h}
$$

with $v_{\mathrm{d}}\left(\mathrm{m} \mathrm{s}^{-1}\right)$ is the $\mathrm{NO}_{2}$ deposition velocity and $h(\mathrm{~m})$ the box height at the ground level.

\subsubsection{Secondary organic chemistry}

The huge number of atmospheric organic compounds and their various molecular structures make organic particle measurements and modeling quite challenging. SOAs, produced through photochemical reactions in the atmosphere contain only oxidized species, carbonyls, carboxylic acid, etc. Pun et al. (2002) and Griffin et al. (2002a, b) propose a very complete modeling system for secondary organic formation and partitioning between gas and particle phases.

Up to now, a very simplified scheme for SOA formation has been implemented in the chemical module MELCHIOR. Anthropogenic aerosol yields (ASOA) come from Grosjean and Seinfeld (1989), Moucheron and Milford (1996), Odum et al. (1996, 1997) and Schell et al. (2001). For biogenic secondary organic aerosols (BSOAs), Pankow et al. (2001) have proposed aerosol yields for terpene oxidation. In the model, precursor volatile organic compounds able to form secondary aerosol species are high chain alkanes, aromatics and monoterpenes. ASOA and BSOA are partitioned between gas and aerosol phases. Mass transfer as discussed in Section 2.6 is not only driven by the gasphase diffusion but also by the thermodynamic equilibrium through a temperature dependent partition coefficient (Pankow, 1994). Using this coefficient, Sheehan and Bowman (2001) have analyzed the importance of temperature effects on SOA partition.

\subsection{Dry and wet deposition}

\subsubsection{Dry deposition of particles}

Dry deposition is classically modeled by a resistance analogy parameterization. The deposition velocity for particles is given by

$$
v_{\mathrm{d}}=\frac{1}{r_{\mathrm{a}}+r_{\mathrm{b}}+r_{\mathrm{a}} r_{\mathrm{b}} v_{\mathrm{s}}}+v_{\mathrm{s}}
$$

with $r_{\mathrm{a}}, r_{\mathrm{b}}$, respectively, are the aerodynamic and quasilaminar resistances for particles and $v_{\mathrm{s}}$ the sedimentation velocity (Seinfeld and Pandis, 1998).

\subsubsection{Wet scavenging of gases}

2.9.2.1. In cloud scavenging. Nitric acid and ammonia in the gas phase are scavenged by cloud droplets. This process is assumed to be reversible. Moreover, for in cloud scavenging, dissolved gases in a no precipitating cloud can reappear in the gas phase due to cloud dissipation. In practice, for gas A, these processes can be written with the two simultaneous reactions (R15) and (R17):

$\mathrm{A}^{\mathrm{g}} \stackrel{k^{+}}{\rightarrow} \mathrm{A}^{\mathrm{aq}}$,

$\mathrm{A}^{\mathrm{g}} \stackrel{k^{-}}{\leftarrow} \mathrm{A}^{\mathrm{aq}}$.

The constants $k^{+}$and $k^{-}\left(\mathrm{s}^{-1}\right)$ are calculated by

$k^{+}=\frac{6 w_{l} \rho_{\mathrm{a}}}{\rho_{\mathrm{e}} D}\left(\frac{D}{2 D_{\mathrm{A}}^{\mathrm{g}}}+\frac{4}{c_{\mathrm{A}} \alpha_{\mathrm{A}}}\right)^{-1}$,

$k^{-}=\frac{6 \times 10^{2}}{\mathrm{RH}_{\mathrm{A}} T}\left(\frac{D}{2 D_{\mathrm{A}}^{\mathrm{g}}}+\frac{4}{c_{\mathrm{A}} \alpha_{\mathrm{A}}}\right)^{-1}$

wwith $w_{1}$ is the liquid water content $\left(\mathrm{kg} \mathrm{kg}^{-1}\right), \rho_{\mathrm{a}}$ the air density $\left(\mathrm{kg} \mathrm{m}^{-3}\right), \rho_{\mathrm{e}}$ the water density $\left(\mathrm{kg} \mathrm{m}^{-3}\right), D$ the droplet mean diameter $(\mathrm{m}), c$ the mean molecular velocity of gas A $\left(\mathrm{m} \mathrm{s}^{-1}\right), D^{\mathrm{g}}$ its molecular diffusion in air $\left(\mathrm{m}^{2} \mathrm{~s}^{-1}\right)$ and $\alpha$ its accommodation coefficient, $H$ the effective Henry's constant $\left(\mathrm{M} \mathrm{atm}^{-1}\right), T$ the temperature $(\mathrm{K})$ and $R$ the molar gas constant $\left(R=8.314 \mathrm{~J} \mathrm{~mol}^{-1} \mathrm{~K}^{-1}\right)$.

2.9.2.2. Sub-cloud scavenging. Dissolution of gases in precipitating drops is assumed to be irreversible, both for $\mathrm{HNO}_{3}$ and $\mathrm{NH}_{3}$. With previous notations, the scavenging coefficient $\Lambda\left(\mathrm{s}^{-1}\right)$ is expressed as

$\Lambda=\frac{p D_{\mathrm{A}}^{\mathrm{g}}}{6 \times 10^{5} u_{\mathrm{g}} D^{2}}\left(2+0.6 R e^{1 / 2} S c^{1 / 3}\right)$

with $p$ is the precipitation rate $\left(\mathrm{mm} \mathrm{h}^{-1}\right), u_{\mathrm{g}}$ the raindrop velocity $\left(\mathrm{m} \mathrm{s}^{-1}\right), R e$ and $S c$, respectively, the Reynolds and Schmidt numbers of drops. Mircea and Stefan (1998) and references therein give relationships between $u_{\mathrm{g}}$ and hydrometer diameter for various types of precipitation. In the model, sulfur dioxide and hydrogen peroxide are also scavenged by precipitation.

\subsubsection{Wet scavenging of particles}

2.9.3.1. In cloud scavenging. In cloud, particle scavenging is difficult to model. Particles can be scavenged either by coagulation with cloud droplets or by precipitating drops. Particles also act as cloud condensation nuclei to form new droplets. This latter process of nucleation is the most efficient one in clouds. According to Tsyro (2002) and Guelle et al. (1998), the deposition flux is written as

$\left[\frac{\mathrm{d} Q_{l}^{k}}{\mathrm{~d} t}\right]_{\mathrm{incl}}=-\frac{\varepsilon_{\mathrm{l}} p_{\mathrm{r}}}{w_{1} h} Q_{l}^{k}$

with $p_{\mathrm{r}}$ is the precipitation rate released in the grid cell $\left(\mathrm{g} \mathrm{cm}^{-2} \mathrm{~s}^{-1}\right), w_{1}$ the liquid water content $\left(\mathrm{g} \mathrm{cm}^{-3}\right), h$ the grid height $(\mathrm{cm})$ and $\varepsilon$ an empirical uptake coefficient (in the range $0-1$ ) depending on particle composition. 
2.9.3.2. Sub-cloud scavenging. Particles are scavenged by raining drops, the deposition flux of particles being given by

$$
\left[\frac{\mathrm{d} Q_{l}^{k}}{\mathrm{~d} t}\right]_{\text {subcl }}=-\frac{a p E_{1}}{u_{\mathrm{g}}} Q_{l}^{k}
$$

with $a$ is an empirical coefficient, $p$ the precipitation rate in the grid cell $\left(\mathrm{g} \mathrm{cm}^{-2} \mathrm{~s}^{-1}\right), E$ a collision efficiency coefficient between particles and raining drops (Slinn, $1983)$ and $u_{\mathrm{g}}$ the falling drop velocity $\left(\mathrm{cm} \mathrm{s}^{-1}\right)$. Assuming a constant drop diameter $(2 \mathrm{~mm})$, this parameterization is an approximation of equations described in Seinfeld and Pandis (1998) and Jung et al. (2002). In the next developments, this equation will be improved.

\section{Simulation of the year 1999 over Europe}

\subsection{Simulation results}

A simulation over Europe has been run for the year 1999. The computing time is about $144 \mathrm{~h}$ for the entire year on a $2.4 \mathrm{GHz}$ monoprocess station (18480 grid points). Year 1999 has been selected due to available measurements for nitrate, sulfate, ammonium and suspended particulate matter on the EMEP web site at http://www.emep.int. Modeling results on $\mathrm{PM}_{10}$ and $\mathrm{PM}_{2.5}$ are presented in Fig. 1, and particulate components in Fig. 2. For comparisons, $\mathrm{PM}_{10}$ and $\mathrm{PM}_{2.5}$ do not account for water in particles. The main cities of the domain generally show high $\mathrm{PM}_{10}$ concentrations mainly due to primary anthropogenic emissions. According to our simulation results for $\mathrm{PM}_{2.5}, \mathrm{PM}_{2.5} / \mathrm{PM}_{10}$ mean ratios are in the range $70-80 \%$. In the South of the domain, this ratio is expected to be overestimated due to resuspended and wind blown dusts (coarse particles) in dry regions (e.g. Spain, Italy) not taken into account. Moreover, dust events from North Africa may occasionally contribute to coarse particles concentration peaks in South Europe (Rodriguez et al., 2002). Because of weak winds and high pollutant emissions, the main polluted area in $\mathrm{PM}_{10}$ seems to be North of Italy. For similar reasons, Eastern European countries show very high concentration levels mainly due to high primary PM emissions and sulfate formation. Sulfate concentrations in the South East of the domain are expected to be underestimated, Bulgaria, an important contributor of $\mathrm{SO}_{2}$ and sulfate is not completely included in the domain. To a lesser extent, from North of France to the Netherlands and Western Germany, high $\mathrm{PM}_{10}$ concentrations are observed. In this region, nitrate is prevalent in PM measurements together with neutralization of ammonia. Annual ammonia emissions in Europe are confined to intensive breeding areas (The Netherlands, Germany, The Po valley in Italy, Brittany in France). These results for nitrate and sulfate are in agreement with Schaap et al. (2002), showing nitrate maximum concentrations in the Netherlands and Switzerland for the 1994-1997 period and high sulfate concentrations in eastern European countries. In spite of important emissions (gas and particles) in Portugal, United Kingdom and Brittany, pollutant concentrations remain low, due to windy and rainy conditions. Modeling results for SOA show the highest concentrations in the North of Italy, mainly due to anthropogenic emissions. A significant biogenic contribution is observed over the Dark Forest and in Central European Countries. In Fig. 2, very high concentrations of water in particles are observed in humid and very polluted regions. As nitrate and ammonium, water in particles can alter measurements during the sampling and conditioning procedures.

\subsection{Observations}

Validation of an aerosol model not only requires an evaluation of $\mathrm{PM}_{10}$ concentrations but also a validation on the main particulate species such as nitrate, sulfate
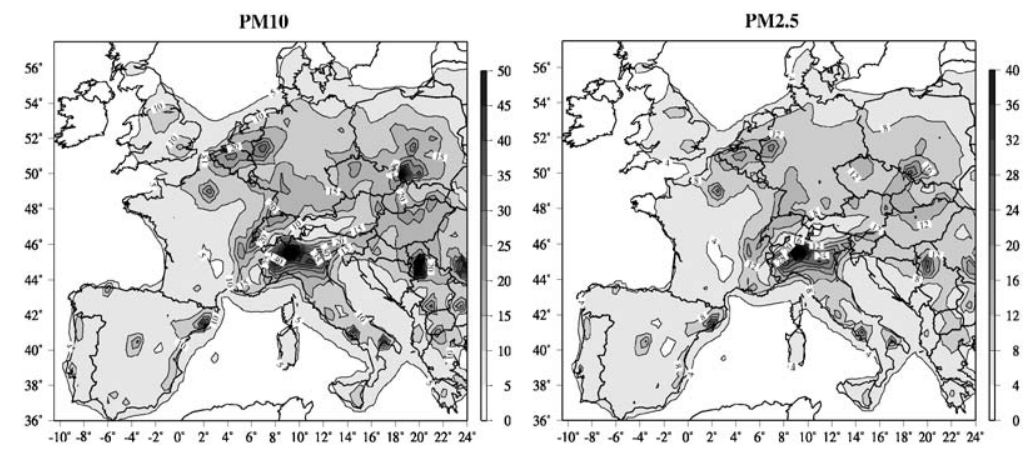

Fig. 1. Modeling results for $\mathrm{PM}_{10}$ and $\mathrm{PM}_{2.5}$ yearly mean concentrations (in $\mu \mathrm{g} \mathrm{m}^{-3}$ ) in 1999 . 

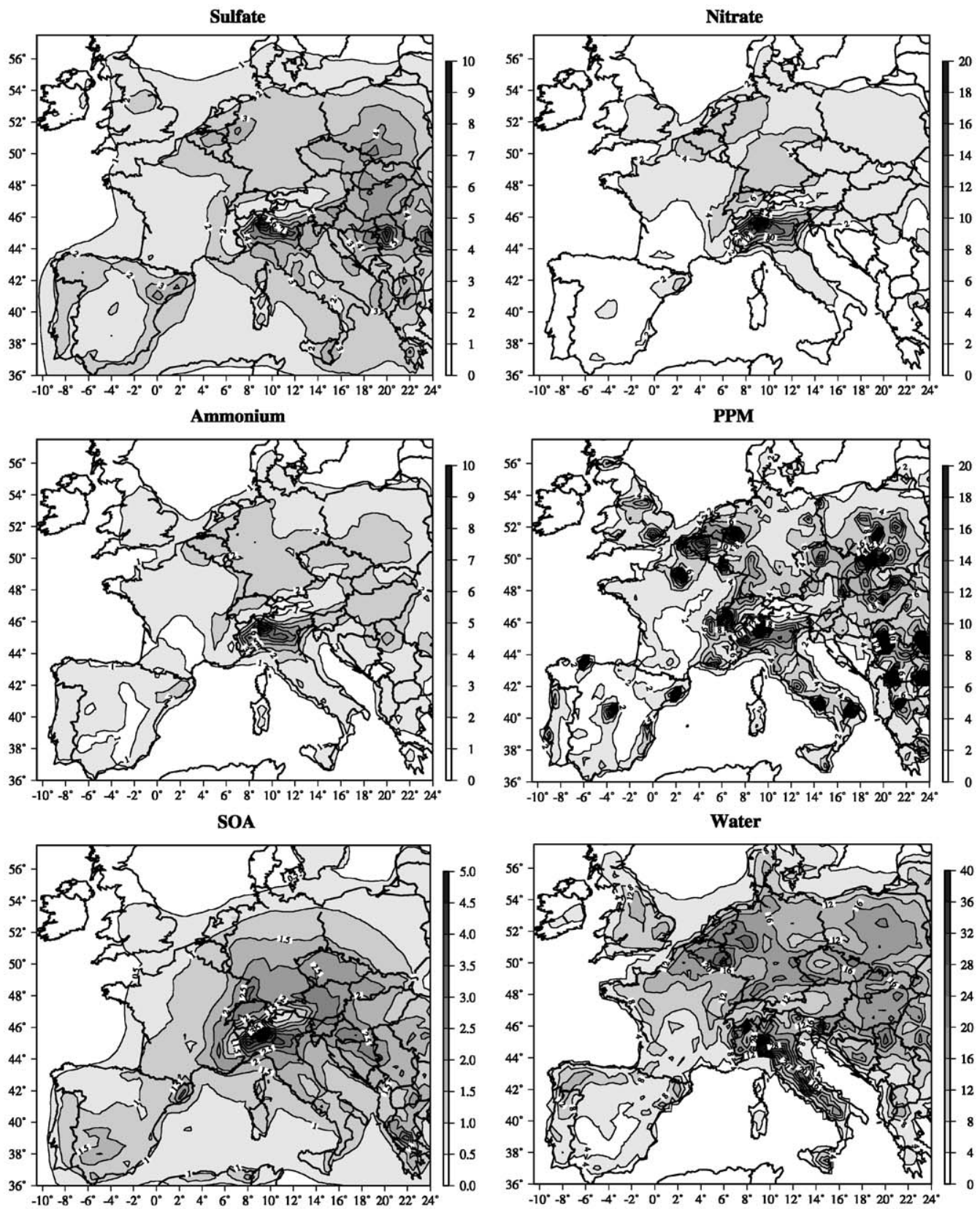

Fig. 2. Modeling results for yearly mean concentrations (in $\mu \mathrm{g} \mathrm{m}^{-3}$ ) of PM components in 1999.

and ammonium. Many reasons could explain the differences between measurements and modeling at EMEP background sites:

(1) chemical and physical processes may be incorrectly simulated

(2) uncertainties on emissions data,

(3) measurement sites may not be so representative,
(4) artifacts in the measurement methods in the sampling and conditioning procedures (condensation, evaporation, reactions, etc.).

Furthermore, the aerosol model accounts for only five components (excluding water). Sea salts, wind blown dusts and resuspended particles are excluded. Although, sea salts are usually assumed to have a weak influence, 
$\mathrm{PM}_{10}$ results are expected to be on the whole underestimated. In this study, 23 EMEP stations, listed in Table 3, have been selected to validate the model in various countries and location types (e.g. coastal, rural and mountainous regions). Comparisons are made for two periods, "winter" and "summer", corresponding to January-March and October-December for the winter period and April-September for the summer period. Most stations measurements are compared to model results at the first model level (50 m layer). At mountainous sites, comparisons at higher model levels are more realistic. Among selected sites, observations for all pollutants are not available, so, only 16 stations are used for $\mathrm{PM}_{10}, 21$ for sulfate and seven for nitrate and ammonium. There is no available data for organic carbon.

Comparisons between simulated and observed $\mathrm{NO}_{2}$ presented in Table 4 allow one to evaluate the model ability to simulate the gas-phase transport and chemistry. EMEP measurement methods for $\mathrm{NO}_{2}$ are different in European countries, these methods sometimes present a positive interference due to other reducible nitrogen compounds like PAN (peroxyacetyl nitrate) or $\mathrm{HNO}_{3}$ (nitric acid). More information about these methods is accessible on the Norwegian Institute for Air Research (NILU) web site at: http://www.nilu. no/projects/ccc/manual/index.html. $\mathrm{NO}_{2}$ observed is directly compared to $\mathrm{NO}_{2}$ simulated, thus, error statistics could be altered. Correlation coefficients in winter are clearly better than in the summer period.
Chemical processes, less predominant compared to transport in winter could explain such differences.

\subsection{PM observations vs. modeling results}

\subsubsection{Sulfate, nitrate and ammonium}

Scatter plots for sulfate, nitrate and ammonium are presented in Fig. 3 at three EMEP sites (NL09, NL10 and PL04). Comparisons between observed and simulated sulfate are presented in Table 5. Normalized errors are usually in the range $30-100 \%$, with correlation coefficients usually in the range 0.30 0.70 . These results on correlation coefficient together with over-estimations (high normalized bias) in winter mean that sulfur aqueous chemistry remain difficult to simulate. Indeed, sulfate being mainly produced in clouds or fogs droplets can precipitate or evaporate to form new sulfate particles, such a cycle is difficult to simulate. Nevertheless, results in Germany are correct in summer. These model performances for sulfate contribute to the debate raised by Reid et al. (2001) about the ability of models to simulate sulfur chemical and physical processes in the atmosphere. This latter paper explains that model deficiencies in simulating sulfur chemistry could be a reason for anomalies in our understanding of sulfur compound trends. Sulfate in aqueous phase is very $\mathrm{pH}$ sensitive. In Europe, $\mathrm{pH}$ is usually comprised in the range 4-6. A very weak error in $\mathrm{pH}$ estimation leads to large variations of sulfate

Table 3

List of EMEP stations

\begin{tabular}{llcrl}
\hline Station & Latitude $\left({ }^{\circ} \mathrm{N}\right)$ & Longitude $\left({ }^{\circ} \mathrm{E}\right)$ & Altitude $(\mathrm{m})$ & Type \\
\hline CH02 & 46.80 & 6.95 & 510 & Rural \\
CH03 & 47.48 & 8.90 & 540 & Rural \\
CH04 & 47.05 & 6.97 & 1130 & Mountainous \\
CH05 & 47.07 & 8.45 & 1028 & Mountainous \\
DE01 & 54.93 & 8.32 & 12 & Coastal \\
DE02 & 52.80 & 10.75 & 74 & Rural \\
DE03 & 47.92 & 7.90 & 1205 & Mountainous \\
DE04 & 49.77 & 7.05 & 480 & Rural \\
DE07 & 53.15 & 13.03 & 62 & Rural \\
DE08 & 50.65 & 10.77 & 937 & Mountainous \\
DE09 & 54.43 & 12.73 & 1 & Coastal influences \\
ES01 & 39.55 & -4.35 & 917 & Mountainous \\
ES03 & 40.82 & -0.50 & 50 & Coastal \\
ES04 & 42.45 & -2.35 & 370 & Coaral \\
ES08 & 43.45 & -4.85 & 134 & Coastal \\
ES10 & 42.32 & 3.32 & 23 & Rural \\
HU02 & 46.97 & 19.58 & 125 & Rural \\
IT01 & 42.10 & 12.63 & 48 & Mountainous \\
IT04 & 45.80 & 8.63 & 209 & Coastal \\
NL09 & 53.33 & 6.28 & 0 & Rural \\
NL10 & 51.53 & 5.85 & 28 & Coastal influences \\
PL04 & 54.75 & 17.53 & 2 & Mountainous \\
SK05 & 47.92 & 19.68 & & Spain \\
\hline
\end{tabular}


Table 4

Comparison of observed and simulated $\mathrm{NO}_{2}$ daily mean concentrations

\begin{tabular}{|c|c|c|c|c|c|c|c|c|c|c|}
\hline \multirow[t]{2}{*}{ Stations } & \multicolumn{2}{|c|}{ Normalized bias (a) } & \multicolumn{2}{|c|}{ Normalized error (b) } & \multicolumn{2}{|c|}{ RMSE (c) } & \multicolumn{2}{|c|}{ Correlation } & \multicolumn{2}{|c|}{ Number of data } \\
\hline & Winter & Summer & Winter & Summer & Winter & Summer & Winter & Summer & Winter & Summer \\
\hline $\mathrm{CH} 02$ & -2.60 & -8.20 & 32.0 & 29.1 & 9.45 & 4.55 & 0.47 & 0.26 & 174 & 177 \\
\hline $\mathrm{CH} 03$ & +48.3 & +62.3 & 55.2 & 63.6 & 11.1 & 6.73 & 0.62 & 0.21 & 180 & 180 \\
\hline $\mathrm{CH} 04$ & -45.3 & -78.2 & 58.1 & 78.2 & 6.65 & 6.92 & 0.32 & -0.04 & 177 & 170 \\
\hline $\mathrm{CH} 05$ & -57.9 & -72.8 & 62.1 & 72.8 & 6.90 & 6.00 & 0.52 & 0.04 & 176 & 178 \\
\hline DE01 & -19.8 & -19.9 & 36.6 & 34.5 & 5.23 & 2.25 & 0.70 & 0.73 & 179 & 169 \\
\hline DE02 & +102 & +117 & 104.9 & 117.8 & 8.88 & 7.01 & 0.65 & 0.34 & 180 & 181 \\
\hline DE03 & +9.30 & -35.4 & 45.8 & 40.3 & 3.04 & 1.81 & 0.74 & 0.31 & 177 & 181 \\
\hline DE04 & +46.3 & +8.10 & 53.4 & 26.8 & 5.85 & 2.10 & 0.56 & 0.36 & 180 & 183 \\
\hline DE07 & +88.4 & +107 & 90.8 & 108.5 & 7.25 & 5.29 & 0.65 & 0.18 & 178 & 182 \\
\hline DE08 & +12.5 & -25.5 & 42.7 & 39.2 & 5.09 & 1.83 & 0.36 & 0.25 & 180 & 183 \\
\hline DE09 & +63.1 & +71.0 & 71.6 & 77.2 & 5.00 & 5.11 & 0.65 & 0.38 & 180 & 183 \\
\hline ES01 & -25.5 & -36.5 & 52.8 & 54.7 & 3.51 & 1.74 & 0.58 & 0.43 & 151 & 177 \\
\hline ES03 & +2.40 & -7.90 & 47.8 & 42.3 & 8.13 & 6.44 & 0.51 & 0.14 & 175 & 181 \\
\hline ES04 & -55.9 & -60.9 & 59.7 & 63.3 & 14.9 & 8.52 & -0.28 & -0.35 & 178 & 173 \\
\hline ES08 & +6.20 & +29.0 & 60.9 & 88.1 & 6.30 & 5.39 & 0.41 & 0.14 & 177 & 179 \\
\hline ES10 & +28.9 & -6.60 & 53.0 & 32.5 & 3.93 & 1.93 & 0.56 & 0.44 & 174 & 182 \\
\hline HU02 & +349 & +281 & 352.0 & 285.8 & 12.2 & 4.71 & 0.41 & 0.01 & 178 & 173 \\
\hline IT01 & +180 & +119 & 181.3 & 121.5 & 27.6 & 16.1 & 0.40 & 0.23 & 170 & 183 \\
\hline IT04 & +85.1 & +74.5 & 89.0 & 77.1 & 20.4 & 10.6 & 0.45 & 0.14 & 179 & 180 \\
\hline NL09 & -3.60 & +29.7 & 35.4 & 44.7 & 7.28 & 4.41 & 0.77 & 0.69 & 172 & 181 \\
\hline NL10 & +39.5 & +61.0 & 43.1 & 62.6 & 11.8 & 13.4 & 0.76 & 0.66 & 166 & 144 \\
\hline PL04 & +39.1 & +32.7 & 64.9 & 45.6 & 3.40 & 1.73 & 0.58 & 0.48 & 175 & 182 \\
\hline SK05 & +23.1 & -26.0 & 60.4 & 47.4 & 6.97 & 2.87 & 0.21 & 0.26 & 180 & 183 \\
\hline
\end{tabular}

References: (a) normalized bias $(\%)$ as Nbias $(\%)=(100 / N) \sum_{i}\left(\left(P_{i}-O_{i}\right) / O_{i}\right)$; (b) normalized error $(\%)$ as Nerror $(\%)=$ $(100 / N) \sum_{i}\left|\left(P_{i}-O_{i} / O_{i}\right)\right|$, and (c) the root mean square error $\left(\mu \mathrm{g} \mathrm{m}{ }^{-3}\right)$ as RMSE $=\sqrt{(1 / N) \sum_{i}\left(P_{i}-O_{i}\right)^{2}}$. $N$ is the number of samples. $O_{i}$ are observations and $P_{i}$ are model predictions.

concentrations. Thus, equations for aqueous sulfate chemistry are very "stiff". Too few observations on nitrate and ammonium are available over the domain. Nevertheless, as previously seen with $\mathrm{NO}_{2}$ comparisons, aerosol nitrate concentrations display their best correlation coefficients in winter, in the range $0.39-0.70$ (Table 6). As described by Hass et al. (2003), performances on nitrate seem better in comparison to those computed for $\mathrm{NO}_{2}$. Normalized errors are generally in the range $60-100 \%$. Our model could tend to "overevaporate" nitrate in summer. In Table 7, comparisons on ammonium species display good correlation coefficients $(0.27-0.79)$ in winter, in spite of large normalized errors. Ammonium seems to be systematically overestimated in winter. The station IT04 located in north of Italy displays important error statistics, certainly due to a deficient simulated horizontal transport. At the site HU02 in Hungary, over estimated boundary conditions could be responsible for the very large errors and positive biases on nitrate, ammonium and $\mathrm{NO}_{2}$.

\subsection{2. $P M_{10}$}

In Table 8, error statistics are presented for $\mathrm{PM}_{10}$, with correlation coefficients often exceeding 0.5 , with usually normalized errors between $30 \%$ and $90 \%$. Results in Germany and Switzerland are usually the best ones. Error compensations between particle components are certainly responsible for a part of these good results, already observed by Seigneur (2001). A systematic negative bias, confirmed by scatter plots in Fig. 3, is observed in many stations (particularly in summer), it could be responsible for the large normalized errors. Some major reasons could explain this bias. As previously discussed, semi-volatile species such as nitrate, ammonium or SOA could be underestimated in summer (evaporated in the model). Moreover, resuspended particles and wind blown dusts not included in the model could significantly contribute to the total PM load. This latter hypothesis is supported by less correct results and very large negative biases observed at Italian and Spanish sites. Besides, Jang et al. (2002) have highlighted the role of heterogeneous reactions onto acid aerosol surfaces in secondary aerosol formation, these reactions not being generally included in most of models.

At the four coastal sites DE01, ES03, ES08 and ES10, correlation coefficients are weak, particularly in winter when the strongest winds occur. Since our model does 

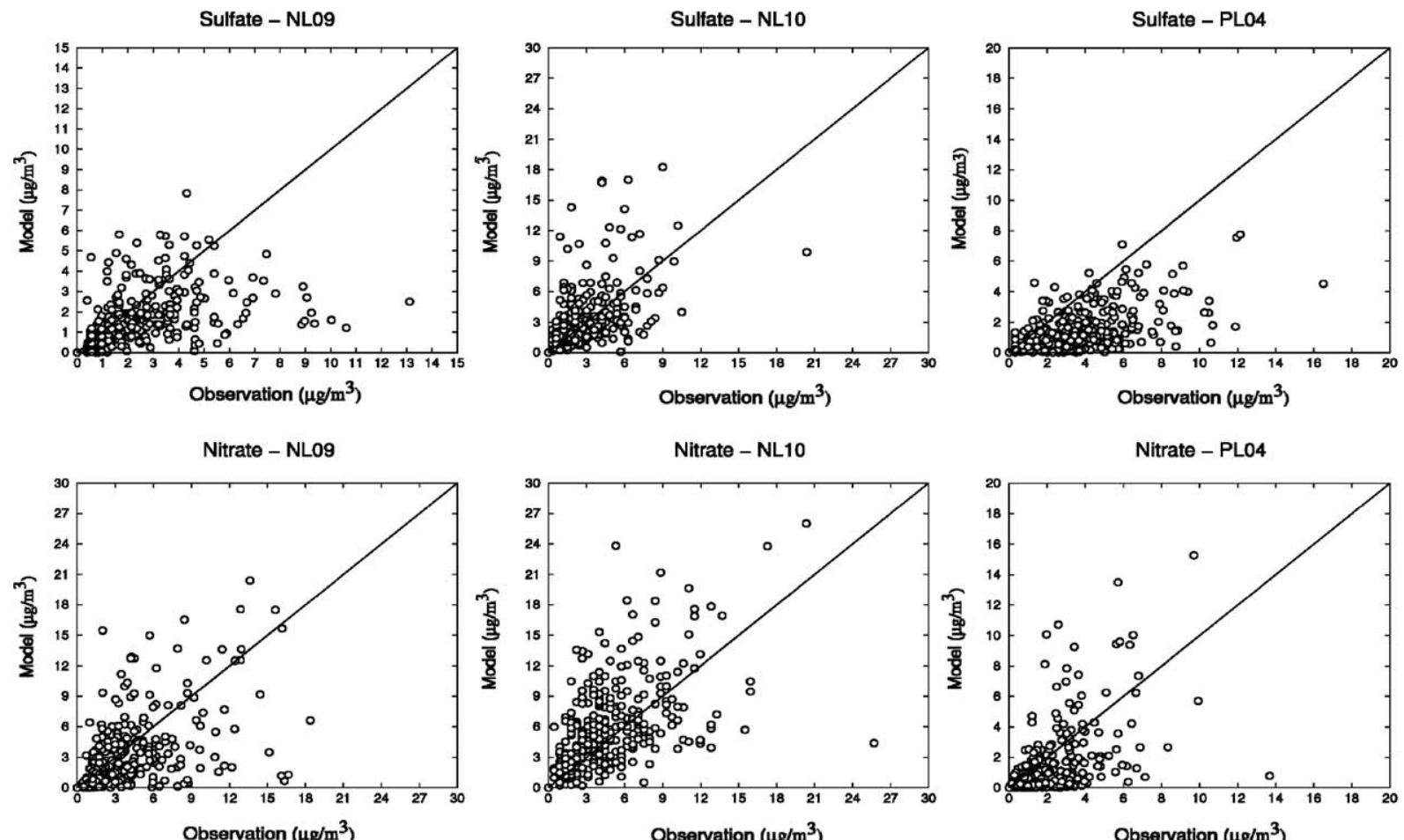

Observation $\left(\mu \mathrm{g} / \mathrm{m}^{3}\right.$
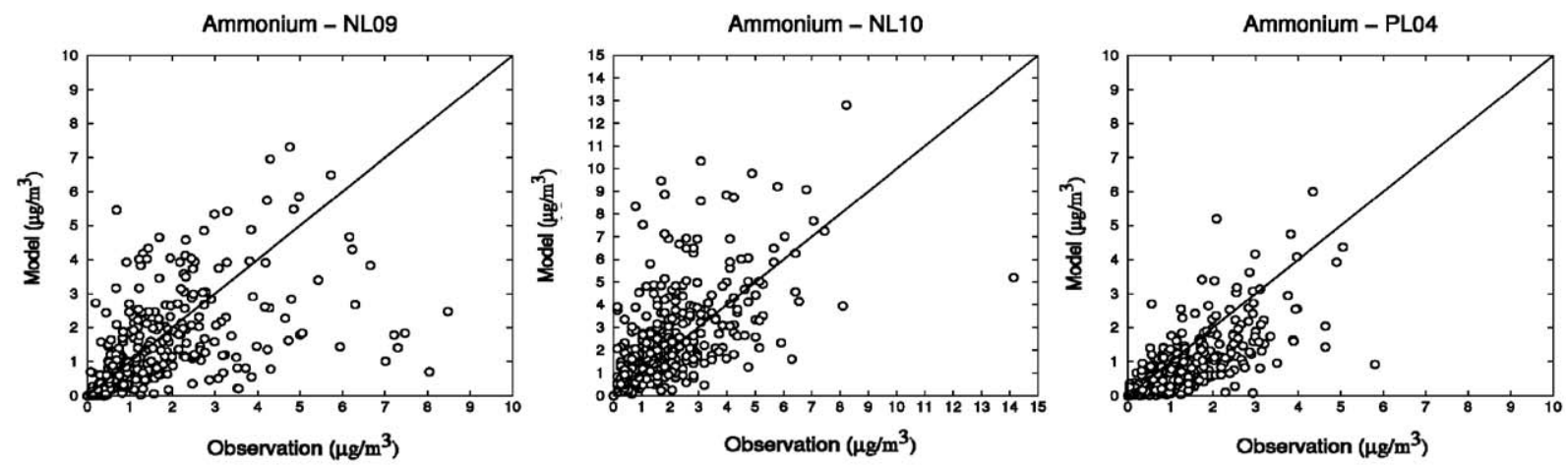

PM10 - $\mathrm{CHO2}$
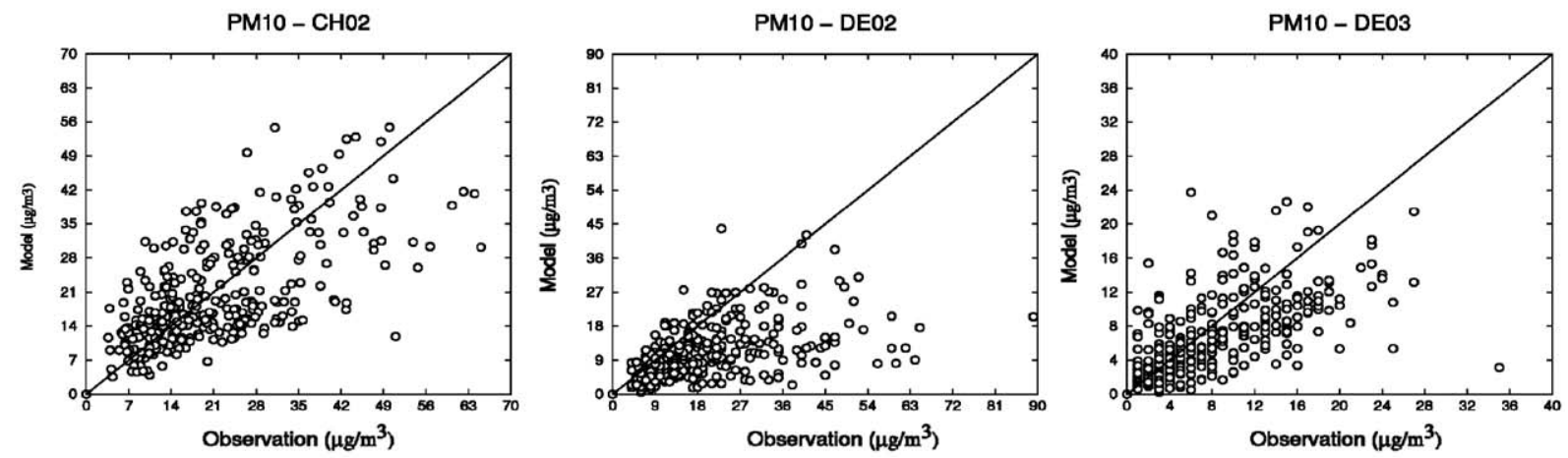

Fig. 3. Model results vs. measurements at different EMEP stations for sulfate, nitrate, ammonium and $\mathrm{PM}_{10}$. 
Table 5

Comparison between observed and simulated sulfate daily mean concentrations

\begin{tabular}{|c|c|c|c|c|c|c|c|c|c|c|}
\hline \multirow[t]{2}{*}{ Stations } & \multicolumn{2}{|c|}{ Normalized bias } & \multicolumn{2}{|c|}{ Normalized error } & \multicolumn{2}{|l|}{ RMSE } & \multicolumn{2}{|c|}{ Correlation } & \multicolumn{2}{|c|}{ Number of data } \\
\hline & Winter & Summer & Winter & Summer & Winter & Summer & Winter & Summer & Winter & Summer \\
\hline $\mathrm{CH} 02$ & +39.1 & -6.20 & 79.9 & 44.1 & 2.05 & 1.22 & 0.39 & 0.47 & 178 & 183 \\
\hline $\mathrm{CH} 05$ & -5.80 & -1.40 & 57.4 & 47.4 & 0.83 & 1.03 & 0.73 & 0.48 & 164 & 181 \\
\hline DE01 & -63.0 & -43.0 & 67.2 & 52.0 & 2.31 & 1.55 & 0.41 & 0.54 & 88 & 143 \\
\hline DE02 & +11.1 & -10.1 & 65.9 & 41.1 & 2.47 & 0.98 & -0.03 & 0.70 & 88 & 152 \\
\hline DE03 & -1.70 & +12.5 & 42.4 & 39.7 & 0.72 & 0.78 & 0.69 & 0.69 & 88 & 153 \\
\hline DE04 & +23.1 & +8.40 & 44.6 & 32.5 & 1.14 & 0.86 & 0.53 & 0.60 & 88 & 153 \\
\hline DE07 & +5.10 & +6.90 & 61.5 & 46.1 & 1.72 & 1.15 & 0.31 & 0.73 & 88 & 153 \\
\hline DE08 & +12.9 & +14.0 & 49.0 & 37.7 & 1.07 & 0.85 & 0.53 & 0.51 & 88 & 153 \\
\hline DE09 & -18.8 & -7.30 & 64.0 & 42.0 & 1.81 & 0.91 & 0.31 & 0.65 & 88 & 153 \\
\hline ES01 & -20.6 & -37.4 & 41.1 & 49.0 & 0.96 & 1.90 & 0.48 & 0.62 & 176 & 179 \\
\hline ES03 & -16.4 & -13.2 & 46.7 & 49.9 & 2.43 & 2.85 & 0.34 & 0.35 & 162 & 173 \\
\hline ES04 & -50.1 & -46.7 & 51.8 & 53.4 & 2.16 & 3.11 & 0.59 & 0.58 & 163 & 163 \\
\hline ES08 & -44.0 & -57.7 & 64.0 & 64.2 & 2.34 & 5.61 & 0.46 & 0.59 & 153 & 160 \\
\hline ES10 & -56.5 & -56.3 & 58.9 & 60.6 & 2.51 & 4.13 & 0.54 & 0.49 & 171 & 170 \\
\hline HU02 & +14.9 & +24.3 & 75.2 & 79.8 & 4.06 & 2.87 & 0.43 & 0.39 & 173 & 179 \\
\hline IT01 & +62.3 & +0.00 & 91.8 & 46.9 & 2.33 & 2.15 & 0.33 & 0.36 & 158 & 175 \\
\hline IT04 & +109 & +33.0 & 147 & 81.7 & 3.75 & 4.00 & 0.41 & 0.46 & 178 & 183 \\
\hline NL09 & -20.1 & -20.6 & 57.3 & 54.8 & 1.63 & 2.33 & 0.51 & 0.37 & 175 & 174 \\
\hline NL10 & +72.7 & -1.60 & 102 & 49.9 & 3.20 & 1.80 & 0.51 & 0.69 & 177 & 175 \\
\hline PL04 & -48.2 & -57.7 & 69.2 & 66.7 & 2.56 & 3.53 & 0.58 & 0.41 & 175 & 183 \\
\hline SK05 & -40.2 & -9.20 & 45.6 & 37.4 & 2.73 & 1.85 & 0.38 & 0.52 & 180 & 183 \\
\hline
\end{tabular}

Table 6

Comparison between observed and simulated nitrate daily mean concentrations

\begin{tabular}{|c|c|c|c|c|c|c|c|c|c|c|}
\hline \multirow[t]{2}{*}{ Stations } & \multicolumn{2}{|c|}{ Normalized bias } & \multicolumn{2}{|c|}{ Normalized error } & \multicolumn{2}{|l|}{ RMSE } & \multicolumn{2}{|c|}{ Correlation } & \multicolumn{2}{|c|}{ Number of data } \\
\hline & Winter & Summer & Winter & Summer & Winter & Summer & Winter & Summer & Winter & Summer \\
\hline HU02 & +749 & -31.1 & 782 & 96.6 & 3.99 & 1.35 & 0.39 & 0.54 & 172 & 179 \\
\hline IT01 & +8.90 & -63.0 & 65.3 & 68.8 & 3.62 & 2.42 & 0.58 & 0.30 & 158 & 175 \\
\hline IT04 & +211 & +30.2 & 220 & 99.5 & 11.5 & 5.30 & 0.63 & 0.23 & 178 & 183 \\
\hline NL09 & -8.10 & -19.2 & 66.8 & 69.0 & 3.06 & 3.79 & 0.70 & 0.32 & 168 & 173 \\
\hline NL10 & +77.4 & +27.2 & 90.6 & 67.1 & 4.01 & 3.84 & 0.65 & 0.44 & 175 & 173 \\
\hline PL04 & -9.70 & -71.1 & 69.2 & 79.8 & 2.11 & 2.00 & 0.62 & 0.23 & 175 & 183 \\
\hline SK05 & -29.4 & -61.8 & 56.2 & 76.7 & 2.08 & 1.51 & 0.40 & 0.59 & 180 & 183 \\
\hline
\end{tabular}

not account for sea salts, model deficiencies at these sites could be explained by our model restriction. During this period sea salts are expected to largely influence PM concentrations in coastal areas. Moreover, at mountainous sites, the model is sometimes deficient. Indeed, at the continental scale, transport is very difficult to model in these regions.

\section{Conclusions}

An aerosol module has been implemented in the chemistry transport model CHIMERE. For short computing times, this model provides simulation results for $\mathrm{PM}_{10}, \mathrm{PM}_{2.5}$, nitrate, sulfate and ammonium species.
CHIMERE is able to provide regional differences in PM concentrations and compositions over Europe: there is a large contribution of sulfate in Eastern European countries and a large influence of nitrate and ammonium in the Po valley and in Benelux. Up to now, performance evaluation of aerosol models for long-term simulations in terms of correlation coefficients, RMSE, normalized biases and normalized errors have been limited. This article gives a complete panel of error statistics using the CHIMERE-aerosol model. Compared to available data, these model results seem fairly reproduce the $\mathrm{PM}_{10}$ variability with satisfactory normalized errors and correlation coefficients (often exceeding 0.50) particularly in Germany and Switzerland. Aerosol modeling results in the North of Italy are over estimated because 
Table 7

Comparison between observed and simulated ammonium daily mean concentrations

\begin{tabular}{|c|c|c|c|c|c|c|c|c|c|c|}
\hline \multirow[t]{2}{*}{ Stations } & \multicolumn{2}{|c|}{ Normalized bias } & \multicolumn{2}{|c|}{ Normalized error } & \multicolumn{2}{|l|}{ RMSE } & \multicolumn{2}{|c|}{ Correlation } & \multicolumn{2}{|c|}{ Number of data } \\
\hline & Winter & Summer & Winter & Summer & Winter & Summer & Winter & Summer & Winter & Summer \\
\hline ES04 & +90.1 & +427 & 123 & 455 & 1.06 & 0.82 & 0.40 & 0.31 & 163 & 163 \\
\hline HU02 & +162 & +192 & 185 & 239 & 1.65 & 1.11 & 0.54 & 0.27 & 173 & 179 \\
\hline IT01 & +70.1 & -0.90 & 93.5 & 54.1 & 1.73 & 1.02 & 0.52 & 0.37 & 158 & 175 \\
\hline IT04 & +419 & +104 & 428 & 132 & 6.50 & 2.15 & 0.41 & 0.32 & 178 & 183 \\
\hline NL09 & +10.7 & -1.30 & 67.8 & 66.0 & 1.16 & 1.61 & 0.70 & 0.38 & 180 & 179 \\
\hline NL10 & +112 & +40.8 & 124 & 83.1 & 2.17 & 1.43 & 0.63 & 0.59 & 176 & 182 \\
\hline PL04 & 5.9 & -39.7 & 67.0 & 59.3 & 0.72 & 0.96 & 0.79 & 0.65 & 175 & 183 \\
\hline
\end{tabular}

Table 8

Comparison between observed and simulated $\mathrm{PM}_{10}$ daily mean concentrations

\begin{tabular}{|c|c|c|c|c|c|c|c|c|c|c|}
\hline \multirow[t]{2}{*}{ Stations } & \multicolumn{2}{|c|}{ Normalized Bias } & \multicolumn{2}{|c|}{ Normalized error } & \multicolumn{2}{|l|}{ RMSE } & \multicolumn{2}{|c|}{ Correlation } & \multicolumn{2}{|c|}{ Number of data } \\
\hline & Winter & Summer & Winter & Summer & Winter & Summer & Winter & Summer & Winter & Summer \\
\hline $\mathrm{CH} 02$ & +28.5 & -5.50 & 49.9 & 30.7 & 11.1 & 7.45 & 0.68 & 0.50 & 167 & 173 \\
\hline $\mathrm{CH} 03$ & +41.4 & +16.9 & 62.4 & 42.9 & 12.0 & 7.11 & 0.65 & 0.45 & 171 & 183 \\
\hline $\mathrm{CH} 04$ & -22.3 & -44.4 & 59.4 & 48.8 & 8.75 & 9.61 & 0.53 & 0.54 & 149 & 166 \\
\hline $\mathrm{CH} 05$ & -48.3 & -42.6 & 57.7 & 53.5 & 10.9 & 9.26 & 0.57 & 0.42 & 177 & 182 \\
\hline DE01 & -76.5 & -75.3 & 77.0 & 75.3 & 30.7 & 17.4 & 0.08 & 0.54 & 175 & 181 \\
\hline DE02 & -21.5 & -48.7 & 35.5 & 50.8 & 8.18 & 17.6 & 0.75 & 0.47 & 177 & 182 \\
\hline DE03 & +34.9 & -13.1 & 75.6 & 40.6 & 5.22 & 4.91 & 0.53 & 0.67 & 166 & 182 \\
\hline DE04 & -14.8 & -33.6 & 34.0 & 38.7 & 6.81 & 7.53 & 0.70 & 0.64 & 172 & 183 \\
\hline DE07 & -14.1 & -37.2 & 38.0 & 42.3 & 8.03 & 10.3 & 0.59 & 0.55 & 180 & 183 \\
\hline DE08 & -15.6 & -41.2 & 52.6 & 47.3 & 6.52 & 9.49 & 0.74 & 0.65 & 180 & 183 \\
\hline DE09 & -59.1 & -62.6 & 59.6 & 63.6 & 13.8 & 14.1 & 0.57 & 0.45 & 180 & 182 \\
\hline ES01 & -68.1 & -82.0 & 68.4 & 82.0 & 16.1 & 26.0 & 0.24 & 0.54 & 168 & 179 \\
\hline ES03 & -75.6 & -75.3 & 75.6 & 75.5 & 30.9 & 31.5 & 0.28 & 0.19 & 161 & 173 \\
\hline ES04 & -79.5 & -82.3 & 79.5 & 82.3 & 29.7 & 27.6 & 0.41 & 0.64 & 160 & 161 \\
\hline ES08 & -77.1 & -82.7 & 78.6 & 82.7 & 23.6 & 31.1 & 0.25 & 0.51 & 113 & 133 \\
\hline ES10 & -76.7 & -79.9 & 76.7 & 84.8 & 38.3 & 42.7 & -0.08 & -0.30 & 140 & 154 \\
\hline IT04 & -8.10 & -36.1 & 44.5 & 55.1 & 31.8 & 36.2 & 0.62 & 0.09 & 178 & 183 \\
\hline
\end{tabular}

of transport modeling deficiencies. For constituent species of particulate matter, modeling results are mitigated. Problems remain in aqueous sulfate formation and heterogeneous nitrate production and further efforts are required to improve this complex chemistry. Secondary organic aerosol formation and partitioning have also to be improved. Seasonal variabilities of statistical errors have been highlighted for nitrate and ammonium. In coastal regions, sea salts could be more significant than usually expected. This study confirms that natural dusts and resuspended particles are essential for models in dry regions and may lead to deficient error statistics (high negative biases).

A validation at the regional scale for smog episodes could help to improve modeling processes and understand model weaknesses. Moreover, PM emission inventories with chemical speciation have to be elabo- rated. In the future, this model could be applied to scenario studies for emission reductions in Europe.

\section{Acknowledgements}

Observation data for this validation have been provided by the EMEP network. The authors acknowledge Robert Rosset and Céline Mari, Laboratoire d'Aérologie, Toulouse, France, Yves Balkanski and Hélène Cachier, Laboratoire des Sciences du Climat et de l'Environnement, Gif sur Yvette, France and Hugo Van Denier, TNO, Apeldoorn, The Netherlands, for scientific support. Moreover, the authors thank the Max-Planck Institute (Hamburg, Germany), $\mathbf{M}$. Schultz, C. Granier, G. Brasseur and D. Niehl for graciously providing us with MOZART data. This work 
was financially supported by the French Environment Ministry (MEDD-Ministère de l'Ecologie et du Développement Durable).

\section{References}

AEAT/ENV/R/0545 Report, 2002. Speciation of UK emissions of NMVOC, N.R. Passant, February.

Ackermann, I.J., Hass, H., Memmesheimer, M., Ebel, A., Binkowski, F.S., Shankar, U., 1998. Modal aerosol dynamics model for Europe: development and first applications. Atmospheric Environment 32, 2981-2999.

Aumont, B., Chervier, F., Laval, S., 2003. Contribution of HONO sources to the $\mathrm{NO}_{x} / \mathrm{HO}_{x} / \mathrm{O}_{3}$ chemistry in the polluted boundary layer. Atmospheric Environment 37, 487-498.

Berge, E., 1993. Coupling of wet scavenging of sulphur to clouds in a numerical weather prediction model. Tellus 45B, $1-22$.

Bessagnet, B., Rosset, R., 2001. Fractal modelling of carbonaceous aerosol-application to car exhaust plumes. Atmospheric Environment 35, 4751-4762.

Cheinet, S., 2002. The parameterization of clear and cloudy convective boundary layer. Doctoral Thesis, Ecole Polytechnique, Palaiseau, France.

De More, W.B., Sander, S.P., Golden, D.M., Hampson, R.F., Kurylo M, J., Howard, C.J., Ravishankara, A.R., Kolb, C.E., Molina, M.J., 1997. Chemical Kinetics and Photochemical Data for Use in Stratospheric Modelling. JPL Publication 97-4, Pasadena, CA.

Fuch, N.A., 1964. Mechanics of Aerosol. Pergamon, New York.

Gelbard, F., Seinfeld, J.H., 1980. Simulation of multicomponent aerosol dynamics. Journal of colloid and Interface Science 78, 485-501.

Griffin, R.J., Dabdub, D., Seinfeld, J.H., 2002a. Secondary organic aerosol 1. Atmospheric chemical mechanism for production of molecular constituents. Journal of Geophysical Research 107 (D17), 4332.

Griffin, R.J., Dabdub, D., Kleeman, M.J., Fraser, M.F., Cass, G.R., Seinfeld, J.H., 2002b. Secondary organic aerosol 3. Urban/regional scale model of size composition resolved aerosols. Journal of Geophysical Research 107 (D17), 4334.

Grosjean, D., Seinfeld, J.H., 1989. Parameterization of the formation potential of secondary organic aerosols. Atmospheric Environment 23, 1733-1747.

Guelle, W., Balkanski, Y.J., Dibb, J.E., Schulz, M., Dulac, F., 1998. Wet deposition in a global size-dependent aerosol transport model. 2. Influence of the scavenging scheme on $210 \mathrm{~Pb}$ vertical profiles, surface concentrations, and deposition. Journal of Geophysical Research 103 (D22), 28875-28891.

Hansen, M., DeFries, R., Townshend, J.R.G., Sohlberg, R., 2000. Global land cover classification at $1 \mathrm{~km}$ resolution using a decision tree classifier. International Journal of Remote Sensing 21, 1331-1365.

Harrison, R.M., Collins, G.M., 1998. Measurements of reaction coefficients of $\mathrm{NO}_{2}$ and $\mathrm{HONO}$ on aerosol particles. Journal of Atmospheric Chemistry 30, 397-406.
Hass, H., Van Loon, M., Kessler, C., Stern, R., Matthijsen, J., Sauter, F., Zlatev, Z., Langner, J., Foltescu, V., Schaap, M., 2003. Aerosol modelling: results and intercomparison from European regional scale modeling systems. GLOREAM, EUROTRAC 2 Report.

Hoffman, M.R., Calvert, J.G., 1985. Chemical transformation modules for Eulerian acid deposition models, Vol. 2. The Aqueous Phase Chemistry, EPA/600/3-85/017. US Environmental Protection Agency, Research Triangle Park, NC.

Horowitz, L.W., Walters, S., Mauzerall, D.L., Emmons, L.K., Rasch, P.J., Granier, C., Tie, X., Lamarque, J.-F., Schultz, M.G., Tyndall, G.S., Orlando, J.J., Brasseur, G.P., 2003. A global simulation of tropospheric ozone and related tracers: description and evaluation of MOZART, Version 2. Journal of Geophysical Research 108 (D24), 4784, doi: 10.1029/ 2002JD002853.

Hov, O., Stordal, F., Eliasen, A., 1985. Photochemical oxidant control strategies in Europe: a 19 day case study using a Lagrangian model with chemistry. NILU TR5/95.

Jacob, D.J., 2000. Heterogeneous chemistry and tropospheric ozone. Atmospheric Environment 34, 2131-2159.

Jacobson, M.J., 1997. Development and application of a new air pollution modelling system-Part III. Aerosol phase simulations. Atmospheric Environment 31, 587-608.

Jang, M., Czoschke, N.M., Lee, S., Kamens, R.M., 2002. Heterogeneous atmospheric aerosol production by acidcatalysed particle-phase reactions. Science 298, 814-817.

Jung, C.H., Kim, Y.P., Lee, K.W., 2002. Analytic solution for polydispersed aerosol dynamics by a wet removal process. Journal of Aerosol Science 33, 753-767.

Kaupp, H., Umlauf, G., 1992. Atmospheric gas-particle partitioning of organic compounds: a comparison of sampling methods. Atmospheric Environment 26A, $2259-2267$.

Kavouras, I.G., Mihalopoulos, N., Stephanou, E.G., 1998. Formation of atmospheric particles from organic acids produced by forests. Nature 395, 683-686.

Krüger, O., Graß1, H., 2002. The indirect aerosol effect over Europe. Geophysical Research Letter 29, 19-1925.

Kulmala, M., Laaksonen, A., Pirjola, L., 1998. Parameterization for sulfuric acid/water nucleation rates. Journal of Geophysical Research 103 (D7), 8301-8307.

Lattuati, M., 1997. Impact des émissions Européennes sur le bilan d'ozone troposhérique à l'interface de l'Europe et de l'Atlantique Nord: apport de la modélisation lagrangienne et des mesures en altitude. Doctaral Thesis, Université P\&M Curie, Paris.

Lee, Y.N., Schwartz, S.E., 1983. Kinetics of oxidation of aqueous sulfur (IV) by nitrogen dioxide. In: Pruppacher, H.R., Semonin, R.G., Slinn, W.G.N. (Eds.), Precipitation Scavenging, Dry Deposition and Resuspension, Vol. 1. Elsevier, New York.

Madronich, S., Flocke, S., 1998. The role of solar radiation in atmospheric chemistry. In: Boule, P. (Ed.), Handbook of Environmental Chemistry. Springer, Heidelberg, pp. 1-26.

Martin, L.R., Hill, M.W., 1987. Catalyzed oxidation of sulfur dioxide in solution: the iron-manganese synergism. Atmospheric Environment 25A, 2395-2399.

Martin, L.R., Hill, M.W., Tai, A.F., Good, T.W., 1991. The iron catalyzed oxidation of sulfur IV in aqueous solution 
differing effects of organics at high and low pH. Journal of Geophysical Research 96, 3085-3097.

Meng, Z., Dabdub, D., Seinfeld, J.H., 1998. Size-resolved and chemically resolved model of atmospheric aerosol dynamics. Journal of Geophysical Research 103, 3419-3435.

Middleton, P., Stockwell, W.R., Carter, W.P., 1990. Aggregation and analysis of volatile organic compound emissions for regional modelling. Atmospheric Environment 24, 1107-1133.

Mircea, M., Stefan, S., 1998. A theoretical study of the microphysical parameterization of the scavenging coefficient as a function of precipitation type and rate. Atmospheric Environment 32, 2931-2938.

Moshammer, H., Neuberger, M., 2003. The active surface of suspended particles as a predictor of lung function and pulmonary symptoms in Austrian school children. Atmospheric Environment 37, 1737-1744.

Moucheron, M.C, Milford, J., 1996. Development and Testing of a Process Model for Secondary Organic Aerosols. Air and Waste Management Association, Nashville.

Nenes, A., Pilinis, C., Pandis, S.N., 1998. ISORROPIA: a new thermodynamic model for inorganic multicomponent atmospheric aerosols. Aquatic Geochemistry 4, 123-152.

Odum, J.R., Hoffmann, T., Bowman, F., Collins, D., Flagan, R.C., Seinfeld, J.H., 1996. Gas/particle partitioning and secondary aerosol yield. Environmental Science and Technology 30, 2580-2585.

Odum, J.R., Jungkamp, T.P.W., Griffin, R.J., Flagan, R.C., Seinfeld, J.H., 1997. The atmospheric aerosol-forming potential of whole gasoline vapour. Science 276, 96-99.

Pai, P., Vijayaraghavan, K., Seigneur, C., 2000. Particulate matter modeling in the Los Angeles basin using SAQMAERO. Journal of the Air and Waste Management Association 50, 32-42.

Pankow, J.F., 1994. An absorption model of gas/particle partitioning of organic compounds in the atmosphere. Atmospheric Environment 28, 185-188.

Pankow, J.F., Seinfeld, J.H., Asher, W.E., Erdakos, G.B., 2001. Modeling the formation of secondary organic aerosol. 1. Application of theoretical principles to measurements obtained in the $\alpha$-pinene/, $\beta$-pinene/, sabinene, $\Delta^{3}$-carene/, and cyclohexene/ozone systems. Environmental Science and Technology 35, 1164-1172.

Pun, B.K., Griffin, R.J., Seigneur, C., Seinfeld, J.H., 2002. Secondary organic aerosol 2. Thermodynamic model for gas/particle partitioning of molecular constituents. Journal of Geophysical Research 107 (D17), 4333.

Reid, N., Misra, P.K., Bloxam, R., Yap, D., Rao, S.T., Civerolo, K., Brankov, E., Vet, R.J., 2001. Do we understand trends in atmospheric sulfur species? Journal of the Air and Waste Management Association 51, 1561-1567.

Rodriguez, S., Querol, X., Alastuey, A., Mantilla, E., 2002. Origin of high summer $\mathrm{PM}_{10}$ and TSP concentrations at rural sites in eastern Spain. Atmospheric Environment 36, 3101-3112.
Schaap, M., Müller, K., ten Brink, H.M., 2002. Constructing the European aerosol nitrate concentration field from quality analysed data. Atmospheric Environment 36, 1323-1335.

Schell, B., Ackermann, I.J., Hass, H., Binkowski, F.S., Ebel, A., 2001. Modeling the formation of secondary organic aerosol within a comprehensive air quality model system. Journal of Geophysical Research 106 (D22), 28275-28293.

Schmidt, H., Derognat, C., Vautard, R., Beekmann, M., 2001. A comparison of simulated and observed ozone mixing ratios for the summer of 1998 in Western Europe. Atmospheric Environment 35, 6277-6297.

Seigneur, C., 2001. Current status of air quality models for particulate matter. Journal of the Air and Waste Management Association 51, 1508-1521.

Seinfeld, J.H., Pandis, S.N., 1998. Atmospheric Chemistry and Physics. Wiley, New York.

Sheehan, P.E., Bowman, F.M., 2001. Estimated effects of temperature on secondary organic aerosol concentrations. Environment Science and Technology 35, 2129-2135.

Simpson, D., Guenther, A., Hewitt, C.N., Steinbrecher, R., 1995. Biogenic emissions in Europe. 1. Estimates and uncertainties. Journal of Geophysical Research 100, 22875-22890.

Simpson, D., Winiwarter, W., Borjesson, G., Cinderby, S., Ferreiro, A., Guenther, A., Hewitt, C.N., Janson, R., Khalil, M.A.K., Owen, S., Pierce, T.E., Puxbaum, H., Shearer, M., Steinbrecher, S., Svennson, B.H., Tarrason, L., Oquist, M.G., 1999. Inventorying emissions from nature in Europe. Journal of Geophysical Research 104, 8113-8152.

Slinn, W.G.N., 1983. Precipitation scavenging. In: Atmospheric Sciences and Power Production-1979. Division of Biomedical Environmental Research, US Department of Energy, Washington, DC (Chapter 11).

Troen, I., Mahrt, L., 1986. A simple model of the atmospheric boundary layer: sensitivity to surface evaporation. Boundary Layer Meteorology 37, 129-148.

Tsyro, S., 2002. First estimates of the effect of aerosol dynamics in the calculation of $\mathrm{PM}_{10}$ and $\mathrm{PM}_{2.5}$. EMEP Report (www.emep.int).

Vautard, R., Beekmann, M., Roux, J., Gombert, D., 2001. Validation of a hybrid forecasting system for the ozone concentrations over the Paris area. Atmospheric Environment 35, 2449-2461.

Vautard, R., Martin, D., Beekmann, M., Drobinski, P., Friedrich, R., Jaubertie, A., Kley, D., Lattuati, M., Moral, P., Neininger, B., Theloke, J., 2003. Paris emission inventory diagnostics from ESQUIF airborne measurements and a chemistry transport model. Journal of Geophysical Research, 108 (D17), doi: 10.1029/2002JD002797.

Warren, D.R., 1986. Nucleation and growth of aerosols. Thesis of the California Institute of Technology, Pasadena.

Wesely, M.L., 1989. Parameterizations of surface resistance to gaseous dry deposition in regional scale, numerical models. Atmospheric Environment 23, 1293-1304. 